\title{
Stakeholder Collaboration in Audience Research: from Why to How
}

\section{$\$$ sciendo}

DAVID MATHIEU, Roskilde University, Denmark; email: mathieu@ruc.dk KIM CHRISTIAN SCHRøDER, Roskilde University, Denmark; email: kimsc@ruc.dk GÖRAN BOLIN, Södertörn University, Sweden; email: goran.bolin@sh.se PILLE RUNNEL, Estonian National Museum, Estonia; email: pille.runnel@erm.ee PILLE PRUULMANN-VENGERFELDT, Malmö University, Sweden; email: pille.pruulmann.vengerfeldt@mau.se ALESSANDRO NANì, Tallinn University, Estonia; email: nani@tlu.ee VIVI THEODOROPOULOU, Independent Researcher; email: vivitheodoropoulou@gmail.com 


\section{INTRODUCTION}

by David Mathieu, chair of the audience and reception studies section of ecrea and associate professor at Roskilde University, Denmark

Stakeholders are a defining aspect of audience and media studies because the field consists of different, sometimes opposing, stakes and these are reflected in the way research is executed. Arguably I - like so many others from the field of audience research - insert my work within a critical tradition in which the interests of the audience, rather than the interests of media, are privileged. Audience research is indeed often conceived as a representation of the interests of media audiences (Das et al. 2018) and implemented methodologically by voicing the audience subjective experiences and perspectives (Livingstone 2010). In such a constellation, the engagement of scholars with stakeholders in order to produce audience and media research has been heavily debated. Precisely because this debate keeps coming back, we may be inclined to think that stakeholder collaboration is hard to ignore for the development of audience research.

Hence, the occasion to gather insights and experiences from a range of scholars with a broad range of varied experiences into a panel to discuss, not only the rationales for engaging with stakeholder collaboration, but how this can be done. However, it would appear that the two questions the why and the how of stakeholder collaboration - often go hand in hand.

Stakeholder collaboration is defined in the context of this panel as the collaboration between academic researchers with non-academic actors who have a vested interest in the field of audience research (media, communication and society) and hence have stakes in the knowledge produced by audience research. It is a different activity than stakeholder consultation, which consists in collecting knowledge, opinions and expertise of stakeholders for, or in the context of, research. The reflections offered by this panel take their point of departure in three interventions that have shaped the conversation on stakeholder collaboration, including the following.

\section{1) As regards Lazarsfeld and the gap} between critical and administrative research, Paul Lazarsfeld (1941) once wrote about the necessary convergence of critical and administrative research, arguing that they have, in fact, a common goal. More than 75 years later, in a research environment dominated by data and online platforms, the gap which Lazarsfeld hoped to bridge seems wider than ever. On the one hand, the knowledge interests, methods and conclusions drawn by critical data studies contrast with the application of big data in other circles of academia and industry. On the other hand, online media have become increasingly opaque and difficult to study for the media scholar, enlarging the divide between administrative and critical researchers as one between those who have access and those who do not. For the independent researcher of digital media use, terms of service often prohibit unauthorized use of data and, by extension for research purposes, access to some online platforms such as Facebook (via their $\mathrm{API}$ ) has become severely limited after the Cambridge Analytica scandal, and algorithms are proprietary tools that are largely considered "impenetrable black boxes" (Paßmann, Boersma 2017).

The answer to such a challenge if we are to believe the struggle of a group of Swedish researchers in their quest to "tear down Spotify" (Eriksson et al. 2019) seems to be a mix of methodological innovation based on digital methods and a strong affirmation of the critical position of research. In such a view, critical research is warfare against the media industry and, by extension, against administrative research. Such a position, however, leads us far away from the vision of Lazarsfeld. While it suggests that changes are needed - notably in how researchers can access data and research objects - it can also contribute to maintain the researcher in the ivory tower 
or turn critical research into the proverbial "barking dog" in the old Arab saying "The dogs bark, but the caravan moves on"; a situation that is neither useful for research nor for society. Thus, an important question for audience research in today's media environment is how critical research can engage in stakeholder collaboration.

At the end of his reflection, Lazarsfeld concludes, "if there is any general rule of thumb in intellectual work it should be the advice never to pass over criticism without exhausting all the constructive possibilities which might be implied in another person's point of view" (1941: 16). Hence, this roundtable asked panellists to reflect on the constructive possibilities that exist for engaging in stakeholder collaboration between actors who may have different stakes. In the words of Lazarsfeld, "how can administrative and critical perspectives in audience research be engaged, even integrated, in stakeholder collaboration?"

\section{2) COST "Transforming Audiences,}

Transforming Societies" and the barriers of stakeholder collaboration

As part of its mandate, the COST Action network "Transforming Audiences, Transforming Societies" (2010-2014) examined the challenges facing stakeholder collaboration, reflecting on both the barriers that academia encounters in its engagement with stakeholders, and also wider issues related to the access by stakeholders to academic research (Bolin, Bjur 2014). Focusing on the former, Bolin \& Bjur identified three sets of barriers including the following: 1) Living in different symbolic and discursive worlds. 2) Asymmetrical relation between academics and stakeholders.

3) Risk that the researcher becomes "the token academic.' While inviting panellists to reflect on the impact that these barriers may have had in their previous experience with stakeholders, we also need to consider ways to overcome, mitigate or avoid these in stakeholder collaboration.
3) CEDAR and the stakes in audience research

CEDAR (2015-2018) The Consortium in Emerging Directions in Audience Research was a network of junior scholars in which I participated, that concerned itself with the future of the field. Based on my experience in co-leading a stakeholder consultation with more than 50 European stakeholders in the field of audience research (Mathieu, Stelhing 2017), I recognize the importance of clarifying one's own stakes vis-à-vis other stakeholders. And yet, this stakeholder consultation has contributed to both define and clarify the network's stakes in the field, especially with regard to researching new objects such as platforms, datafication, or the internet of things, for which the stakes involved were far from obvious to begin with. [See Ytre-Arne, Das 2019 , for the outcome of this reflection into a 5-point agenda for the future of audience research]. In doing this consultation, we fully realised that academic researchers are also important stakeholders that, given their knowledge, should actively participate in defining the stakes involved in their research.

Therefore, an important task of audience research is precisely to define stakes. Echoing Martin Barker's keynote at the TATS COST conference in Ljubljana (2014), entitled "Whose Side Are We On?" it is essential for research to distinguish its stakes from other, especially competing, stakes. Such a position begs many questions for our engagement in stakeholder collaboration. Should the definition of stakes be an activity that is to be carried independently or in collaboration with stakeholders, especially when the latter can enrich our insights? How can the perspectives of stakeholders be integrated in such an endeavour? Does critical research essentially consist in imposing its definition of the stakes on non-academic stakeholders?

This roundtable takes these existing conversations further by focusing on the "how" of stakeholder collaboration, rather 
than the "why." In a research environment characterized by data abundance, yet also by opacity, stakeholder relation has become a controversial necessity. The question, then, is how to engage in collaboration with stakeholders that is neither naïve, nor idealistic.

\section{KIM SCHRØDER, professor, Roskilde University, Denmark}

Today, I arrived a bit late for this conference, because I participated in a workshop with a stakeholder. I thought this would make a good introductory remark to this roundtable. The stakeholder in question is Danmarks Statistik - the statistical office of Denmark. They are in the process of revamping their entire framework for making statistics about the media landscape, in order to better grasp the advent of digital and social media, which are not really part of what they have been doing so far - not sufficiently, at least. They had invited people from the industry and from academia to assist them in setting up the category system to measure production, distribution and consumption of the complex crossmedia landscape.

For me, it is rewarding to participate in this exercise, because I learn that my research holds value for a significant actor in society, who uses this to create better understanding about the media scene for everyone who uses these statistics. Kim Schrøder

My contribution consisted of giving feedback to their ideas about what to measure and how to operationalise the conceptual inventory. For their statistics about news media content, they have decided to adopt some categories that I set up in a study I published for the Reuters Institute in February. For me, it is rewarding to participate in this exercise, because I learn that my research holds value for a significant actor in society who uses this to create better understanding about the media scene for everyone who uses these statistics. So, hopefully, it is reliable documentation about the media landscape, you could say, that is coming out of this. But it is also valuable for me, because I learn how to sharpen my thinking about things like "repertoires," which is central to my work, and about what defines niche media, for instance, which are things that I can incorporate into my research.

As you may already have guessed from my anecdote, I am more on the symbiotic part of the equation than the adversarial, although of course I recognise that in some areas there are adversarial relations. But the title of this roundtable was "From Why to How" and I think the best way to illuminate this area is to describe some of the "hows," for instance, how we have experiences with stakeholder relations and stakeholder collaboration.

I think it is very hard to generalise about stakeholder relations; to look over the whole field of all possible collaborative relations between academic researchers and non-academic researchers [the industry for instance] and arrive at some sort of overview. Some scholars have tried to do this and Paul Lazarsfeld was one of them, with his well-known distinction between administrative and critical research. And I think the reason why we keep going back to this - at least the reason why I keep going back to this dichotomy - is precisely that it expresses both the difference, and also the reciprocity, between these two stances. There may be different interests, but also possible common ground in building knowledge about the way media are used in a socio-cultural context.

Another example of mapping and reflecting on stakeholder relations, about which I have some first-hand knowledge, is the COST Action "Transforming Audiences, Transforming Societies," that took place in the four years 2010-2014, and which published a report entitled "Building Bridges: Pathways to a Greater Societal Significance for Audience Research" (Patriarche 2013). The report was the result of extensive consultations with relevant stakeholders, and 
testimonies from more than 100 audience researchers across Europe. The report on stakeholder relations was based on the members of the working group within the Action that I chaired and was crafted by a small a task force consisting of Göran Bolin, Lars Nyre, and Jakob Bjur (Bolin, Bjur 2013).

The point of departure of this report is the need to cultivate stakeholder relations because of the obligation of academic research to demonstrate public value and societal impact, which is also something that is now built into research grant applications. If you do not demonstrate public value immediately at the stage of applying for funding, you will not get it or it will be difficult. And such public value, this report says, can be produced for a range of stakeholders - policymakers, regulatory bodies, media industry professionals, civil society and the public at large.

Although it is often said - and it is
often true - that industry actors
and academic researchers live
in different worlds, and have dif-
ferent needs, there are multiple
cases, where they have shared
interests, such as to build knowl-
edge about audiences that benefit
both their strategic ends and the
wider societal interests. -
Kim Schrøder

Another keyword in this report is 'liaison.' In order to demonstrate public value, academic researchers have to liaise with one or more stakeholders, if the stakeholders want to - which, apparently, they do not always. This liaison can be in the form of simply disseminating and communicating one's research findings in such a way that they actually reach interested stakeholders. The liaison can also take the form of drawing on the assistance of these stakeholders. This is one of the things discussed by Lazarsfeld, as he describes how academic researchers may need to collaborate with industry actors, in order to gain access to the empirical material whose analysis can help confirm established theories or help generate new ones. Here, the actors outside academia, in the media industry or in governments or research institutions, deliver raw materials for the researchers, who then proceed to produce knowledge that is useful for these institutions and for other stakeholders.

But stakeholder relations may also take the form of more symmetrical collaborative relations. Although it is often said and it is often true - that industry actors and academic researchers live in different worlds and have different needs, there are multiple cases in which they have shared interests, such as to build knowledge about audiences that benefit both their strategic ends and the wider societal interests. Of course, it has to be said that although there are many pressures now to engage in stakeholder collaboration, there exists no absolute imperative that requires academic researchers to collaborate. And this was quite clear in the COST report which stated that "it is important for the advancement of audience research as an agent, sometimes critical of human enlightenment about the media/society nexus, that it continues to rest on a solid base of interest-free knowledge objectives" (2014: 12).

So, academic research should insist on the privilege to sometimes follow a path that - at the outset at least - no one considers valuable. However, at other times, the report says, there are no adversarial relationship but that "while one could have anticipated strongly opposing views between academic and non-academic groups, it appears on the contrary that there are many converging perspectives" (2014: 12). I already told one anecdote about such collaborative relation, and I will mention a couple of other examples which focus on the "how" of stakeholder relations, as I have experienced them.

The first example is about methodological innovation. One quest as an audience researcher has been to cultivate innovative paths in the area of mixed methods, and to explore the ways in which qualitative and quantitative methods can be complementary. This is my quest as a researcher 
for audience knowledge. In order to operationalise this mission in the form of empirical research, I have sought the knowledge of stakeholders outside academia, who had convergent interests, albeit with motivations that were different from mine. My motivation has always been to expand and solidify the pool of knowledge that societies need to improve the human condition. This sounds very lofty, but I guess we have to be a bit lofty in these matters.

\section{In order to operationalise (...) empirical research, I have sought the knowledge of stakehold- ers outside academia, who had convergent interests, albeit with motivations that were different from mine. - Kim Schrøder}

This quest of mine has been about exploring what insights can be produced with Q-methodology. And when my interest in Q-methodology was emerging in the early 2000s, I found out that I could cultivate this interest by collaborating with the ACNielsen market research company. They had an interest in adding a potentially-powerful new tool to the toolbox they offer to customers who wish to have better impact on consumers, or NGOs aiming to increase people's donations, and so on. Through this collaboration, we shared the cost of the fieldwork, we collaborated on the analysis, and we co-authored scholarly publications.

A similar thing happened in my research on news audiences. This was a project primarily funded by the Danish research council. I found a collaborating stakeholder in the Danish newspaper Politiken, and the head of research there, Bent Steeg Larsen. This project was founded on a common desire, which was in the early stages of the digital revolution in journalism, to understand news audiences better - how their navigation in the landscape of old and new news media was anchored in the concerns of everyday life. And again, we shared the costs of the fieldwork; Politiken hosted the interview sessions, we operationalised the media array of legacy and digital/social media to prompt informants together through the pilot stage and we co-authored an article for Journalism Studies (Schrøder, Larsen 2010).

I have other examples - one from the DREAM project about museum visitors and collaborating with museums about improving the experience of visitors in the museum. The other is about advising the ministry of culture's media panel, in order to promote enlightened media regulation, in a way similar to what I was talking about in my first example, about stronger explanatory power for national media and audience statistics. There could be many other examples. But I think I will stop here, and I think my point is clear; that my experience is mainly a positive one. It is possible, obviously, that this positive experience with stakeholder collaboration stems from my research not being critical enough. Be that as it may, I have found fertile ground with the stakeholders I have sought or who have sought me.

\section{GÖRAN BOLIN, professor, Södertörn University, Sweden} Lazarsfeld has already been mentioned in the discussion, and I also wanted to take my point of departure in his article from 1941. One of the main points of this article was that the administrative and the critical research were beneficial for each other, whereas I presume that the reason why he emphasised this was that this was not evident, neither for stakeholders nor for the administrative researchers or the critical researchers. The critical researchers - one of the main figures he thought, of course, was Theodor Adorno with whom he collaborated in his music and radio project. Lazarsfeld was working at that time [1941] in a group within the framework of the Rockefeller foundation. They were funded by them, together with Harold Lasswell and Robert Lynd. Robert Lynd had published a couple of years earlier, in 1939, a book called "Knowledge for What?" in which he reflected on the role of social science in society. In the concluding chapter of the book he summarises the discussion on the 
character of social science saying, "The controlling factor in any science is the way it views and states its problems" (Lynd 1939/1970: 202). He was emphasising the way in which we frame the problem; the way in which we phrase our research questions. I will come back to this in due course, giving some examples.

Stakeholders are stakeholders because they have a stake in something. So, we come immediately to questions of power. Power over knowledge evokes Habermas, as he discussed in "Erkenntnis und Interesse" the research interests that we have (Habermas 1968/1972). We have an interest in knowing something, for example, about the audience. And I will try to explain shortly how a sound academia-stakeholder relationship builds on some sort of equality of power; that these two fields are somewhat equal in power. As concerns "fields," I am referring to fields in terms of Bourdieu - as the academic field versus the commercial field. In Bourdieu's theory, one who achieves power will also have autonomy to act and to phrase research questions the way they wish. (Bourdieu 1993).

\section{A sound academia-stakeholder relationship builds on some sort of equality of power - Göran Bolin}

So, this is about the "how" - how do we achieve this? How do we achieve a sound stakeholder-researcher relationship? I think this is - as Kim already hinted especially important for a field like ours, of media studies and especially, perhaps, for audience research since audience research is produced mostly from within the broadcasting corporations and the media business themselves. My former colleague Cecilia von Feilitzen, who sadly passed away last year, used to point out that most of our knowledge about audiences is produced from within the media companies themselves. So, there is also a competitive situation here, between those who produce knowledge about audiences within and outside of the academy. I will give you two examples from my own experience that can point to 'how' - one good and one bad example.

The first one is the bad example at least to me. When I was a very young researcher - before I even started my PhD training - I was commissioned by the Swedish Ministry of Culture (Kulturdepartementet) together with Olle Sjögren from cinema studies for a project as part of the larger state report. This was in 1991 - so, we had the debate on video violence and all these video films that flooded the countries of Europe, and many of them were violent; and then they circumvented the existing legislation, the censorship of Sweden and those countries that had censorship. So, the commission was to map the types, because this state department wanted to know, what films are these, and what types of films and what types of violence do they contain.

For about a year, I watched enormous amounts of horror and action and "slasher" movies, which was, in a way, interesting. But the task for me was also to write a report - that was supposed to be the basis for the larger state report - SOU 1993:39. When I handed in that report to the Department Secretary, I heard nothing for a week, and then I got a fourteen-page letter in reply. It was not very appreciative of what I had written. My undergraduate background was in cinema studies, so I did a genre analysis. What types of films are these? How can you characterise the types of violence in them? Who are the perpetrators, who are the victims, and who are the heroes? One of the things the Department Secretary reacted to most was that I had used the concept of "aesthetics of violence". I think two of these fourteen pages insisted you cannot combine aesthetics and violence. This surprised me, as I said I was coming from cinema studies. When the final state report arrived, it said next to nothing about our findings. It merely concluded that the researchers had emphasised asking other questions, without mentioning which other questions (SOU 1993-39: 41-43). So, this is how we come back to the power to formulate your own questions. I was, of course, quite 
young - had not even started my PhD training - so could not do much about it. My standing in the field was quite weak at that time. [My report was later published by my department; Bolin 1993].

The better example I have occurred some ten years ago when I was involved in the large historical project on broadcast media in Sweden, funded by a private foundation that was owned by the public service broadcasters in Sweden (SVT, SR and UR), but also commercial broadcaster TV4 and Teracom, the company that owns the networks. I was in the editorial committee since the main objective for the project was to produce a number of books. I think there were some 40 books produced in all. I was in the editorial board, and we had meetings around the drafts that the authors successively produced. Within that board was also Göran Ellung, then program director at TV4. As we were meeting on a regular basis (roughly every third month for a number of years) Ellung and I became more closely acquainted, particularly because of his comments on things. I learned from those comments. He said some things from his standpoint as a program director of TV4 that gave me insights that I could not get otherwise. And I like to believe that he felt the same, which is why we eventually came to collaborate between Södertörn University and TV4, where they funded a visiting professor in practical media production for three years. This cooperation ended for financial reasons. But that was a very fruitful cooperation and, on the basis of that, Göran Ellung knew that we asked different questions than they did at the audience research department at TV4. So, we could learn from each other.

You do not develop good stakeholder-academia relations because you do the same thing, but because you do different things - Göran Bolin

I think this illustrates the point that I have tried to make here - that you have to have some sort of equality in power, that you have to have some recognition for producing the type of knowledge that cannot be produced within the other organisations. That is, you do not develop good stakeholder-academia relations because you do the same thing, but because you do different things.

\section{PILLE RUNNEL, research director at the Estonian National Museum, Estonia}

The field I am mostly currently involved with is museum communication. During past years, a lot of it had to do with developing, and then opening, the new building of the Estonian National Museum in the fall of 2016. We merged some communication research in the development processes, particularly in the field of exhibition development, where I was involved in several different roles and continue in audience research now, as the exhibitions are opened.

Museum communication is a wide concept, but our research at the ENM was particularly focused on the issues of museum participation and audience engagement an approach that is rooted in participatory communication research. If I say "museum participation," I recognise myself as a scholar, stepping into a particular situation or approaching an issue to be solved from the perspective of audiences and future audiences in particular, rather than from the perspective of the museum/ exhibition producers. When asking research questions about the audiences rather than about the production, while simultaneously being fully engaged with exhibition production, our research dealt with a new permanent exhibition viewed more from the perspective of potential visitors, audiences and users. Imagining audiences is in some ways part of the exhibition production processes, but more in terms of structural requirements (resources, norms and rules related to the exhibition production) or visitor's imagined personal (agential) needs in relation to the exhibition content [which forms the ground of marketing the exhibition or its future layer of educational activities] and 
less in terms of different modes of engagement, literacies or exhibition formats.

The exhibition production process was inevitably a major undertaking in stakeholder collaboration and I noticed that, when we developed 'on-site media solutions' at the museum's main permanent exhibition, I often found myself giving up the role of the critical audience scholar and instead advocating for future visitors and audiences while taking the role of the representative of the museum institution.

When elaborating the initial design ideas with media designers, I relayed my scholarly knowledge regarding the usage preferences, usage patterns and repertoires of media audiences. But when the process moved over to negotiating solutions and eventually making decisions, my role as a museum administrator and museum curator took over, foregrounding structural (resource-related) aspects. Likely, the discourse of the audience scholar in this applied research/stakeholder collaboration was not sufficient for managing the complex processes of exhibition production. This process also demonstrated the fluidity of doing this kind of applied research in a very complex situation, while collaborating with different stakeholders.

When looking back to this experience of curating the exhibitions while simultaneously studying the process, it could have been framed from the very beginning within the approach of action research, which has the capacity to actively change the situation under investigation, but also an approach which is prepared to accommodate these fluctuations in the processes as well as in the roles of the participants. As kind of activist researchers, we brought into the process what we thought we were lacking in the particular exhibition production practice, both from the side of the curators and the perspective of exhibition designers including academic expertise regarding audiences, media processes and media formats. But the recognition of doing action research came later.
In the museum field, stakeholder collaboration has meant playing a lot of different approaches, methodologies and experiments, and sometimes finding difficulties in explaining that to the academia Pille Runnel

To sum up my first example as an audience researcher in the museum field, stakeholder collaboration has meant putting forward a lot of different approaches, methodologies and experiments, and sometimes finding difficulties in explaining that to the academia.

l'd like to explain another encounter which involved stakeholder collaboration concerning a major survey and different expectations related to it. In 2018, I was involved in a commissioned research targeting Estonian creative industry's cultural heritage areas [museums and libraries] with a focus on visitors and audiences and, in particular, the reasons for visiting museums and libraries, or not. It was the first national representative survey regarding museums and libraries in Estonia. Uniquely, the survey was to simultaneously explore and compare two cultural heritage sub-areas (Möller, Runnel, Põldaas 2018). Assessment of the services was not an initial purpose of the study; rather, the suggested target was to better understand different visitor and non-visitor segments. Thus, the research company making a tender invited me as a museum practitioner and audience scholar, and another scholar from the field of libraries, to join the team as particular experts in audience and user research.

Besides being a relevant research experience, this remit also gives rise to an insightful account on stakeholder collaboration. The study design was original in the sense that instead of proposing the research problem and preferred research approach, the initial task description involved a relatively fixed methodology and an almost ready-made questionnaire. Only then were partners involved who would carry out the research. 
The survey was commissioned by Enterprise Estonia on behalf of the Estonian Ministry of Culture. One of the areas of responsibility for Enterprise Estonia is developing tourism market and services within the framework of long-term strategic objectives of the Estonian economy. Accordingly, the concept of visitor research was likely developed from the point of view of the entrepreneurship-centric expertise available within this institution, rather than derived from the studies of audience engagement and museum/library development. Thus, instead of a survey on visitors as audiences and users, the questionnaire embraced the study from the point of view of quality assessment of the current services offered by the heritage sector, as well as identifying a number of potential future services to be developed.

The commissioning party had identified the size of the sample as well as methodology. While the representative sample of the population which would be in accordance with the population structure was overestimated $(n=2000)$, the size of the second target group - companies across all sectors of economic activities was too small $(n=200)$ to produce any valid conclusions regarding their visiting and non-visiting patterns. I can assume, but not verify, that the sample sizes were seen not primarily as tools for knowledge generation, but rather as procedural elements based upon the available budget. The initial population survey was extended to the business sector, but only partially.

As research experts engaged with stakeholder collaboration, we do not necessarily realise all the expected areas of impact of the study that may be significant for the stakeholders. For example, in this collaboration it became apparent during the finalizing of the questionnaire design that, in some cases, the questions to be included were not necessarily grounded in audience demographics or knowledge regarding existing consumption and usage patterns, but were informed by the ongoing internal operational issues and challenges among the stakeholders, including policy and funding debates. Thus, I eventually took the stance that the stakeholder representative in the field of development of Estonian Libraries was not to be challenged with academic considerations when she advocated for questions to be inserted in order to provide data directly to ongoing negotiations for state investment into the sector. It became apparent that some direct, practical results regarding some aspects were needed, rather than just more complex interpretations made by crossanalysing the results of different sets of questions.

Besides the negotiations regarding the survey design, commissioned research is always framed by legal considerations (rather than, for example, ethical). As the report had to limit the issues presented, we as involved experts saw additional issues, as well as opportunities which were significant enough to possibly carry out additional research with both academic and applied research value with no additional funding needed. At the time of this presentation, the negotiations with the legal department of Enterprise Estonia were ongoing over the legal aspects of potential future work. In order to give permission, the legal department requested explicit statements regarding where and when the additional analysis would be published (indicating the respective journal) and what the results of this additional analysis were going to be ${ }^{1}$. The failure to explain the academic work process - from forming the research questions, to the application of academic peer-review, to publishing research papers - proved the biggest power imbalance between academic researchers and the stakeholder, as the negotiations were removed from the field of audience and user studies and replaced with legal discourse. Till now, the further academic work linked to the study has only used references to the basic analysis carried out under the contract. It is likely that with every commissioned and well-funded study (involving both public and private

Personal correspondence. 
stakeholders), there is a high possibility of running into legal issues both in cultural and media industries. Perhaps these legal issues should be added to curriculum so that students may become familiar with them at the beginning of their studies. As an expert scholar, you have likely no time to go back to the basics of law, and mostly likely your research team will not have a legal representative.

To sum up, this stakeholder collaboration could be interpreted both as a success and a failure. Different from an academically designed study, the path from the expected goal to the actual collaboration with stakeholders was not straightforward, as the goals had been defined from very different disciplinary and professional backgrounds, contexts and agendas. However, despite occasionally failings in joint decision making, the collaboration over the national study was still beneficial. For a scholar, the opportunity to carry out representative quantitative survey in this area of audience research would not otherwise have been possible.

As a scholar, this was a very good experience, because it would have never been possible to collect this size of sample in this field without stakeholder collaboration Pille Runnel

A final relevant aspect of this collaboration has to do with communicating the results of the study across numerous presentations and training sessions for museum and library sector professionals. Since communication was entrusted to the hands of the researchers who were actual authors of the final report, it was possible to discuss the results of the study in an open manner, diminishing the agendas of the stakeholders, which were not so relevant in these particular contexts. The professional community was eager to listen and debate the results from a more egalitarian position.

\section{PILLE PRUULMANN- VENGERFELDT, professor, Malmö University, Sweden}

It is possible we overlooked the notion that we know what we mean by stakeholders. And I think that is an interesting position, because, as David was saying, we are doing stakeholder collaborations but we are representing the audiences in relation to those stakeholders, to a certain extent.

Our job as researchers is to bring the voice of audiences to the media industry, cultural industry, statistics office or other entity. But at the same time, who are the audiences that we are representing? Are they also stakeholders? Do they actually want us to represent them in the way that we do?

I just recently got a rejection for a Horizon project, in which we had extensive collaborations with museums and universities, and we got criticized for not including stakeholders. So, the definition of "stakeholders" or the understanding of who is considered to be a valid stakeholder in relation to research collaborations fluctuates widely. Reviewers were actually expecting that we had the marginal non-visitor audiences as part of our management team, which in my opinion is not really a feasible or reasonable expectation because stakeholders in audience position are often very diverse and fragmented. It is very difficult to say to a person on a street, "okay, you are now representing the audiences!" "Thank you! Yes! Of course! I will definitely do that"... Many Horizon projects might be doing that; picking random people on the street, and saying, "you are representing our stakeholder now".

Another aspect I want to reflect about is how we actually build long-lasting relationships. Because I think some of those examples that others have brought here have indicated that good-quality or rewarding stakeholder collaboration is often built on trust, on reputation; that the scholar being part of a stakeholder-collaboration is either trusted because of existing longterm collaborations, or the scholar is trusted because of their established reputation. 
It takes time to build good relationships and achieve better collaborations - Pille PruulmannVengerfeldt

The experience I have had is that it takes time to build good relationships and achieve better collaborations. Working with the Estonian National Museum (Runnel, Pruulmann-Vengefeldt 2014; PruulmannVengerfeldt, Tatsi, Runnel, Aljas 2014), we started working together on this idea of a project in 2008. We got funded, we started doing seminars, and I think it was 2011, and I was still thinking that I am just talking to a wall. I am making no progress. The museum practitioners are looking at me like an alien; they do not really like what I am telling them. It took about two or three years before someone came to me and said: "you know, we actually implemented one of your suggestions!" And I said "yes!" But it took years and years.

And it took years of persistent work and doing bi-monthly seminars. We tried and tried. I was in a position where I was introduced to the organisation by Pille Runnel, research director and was very much an insider with established position and long experience. I was invited as an external expert with a trustworthy reputation. But it still took ages to build that kind of relationship so that stakeholders could say: "we actually do trust what you have to say." So collaboration involves this kind of resonance. And having now moved from Estonia to Sweden, I find that it takes ages to build up reputation as an external scholar, as an international scholar. I have sent e-mails to museums, saying "I want to collaborate," and had no response. Establishing collaborations takes time and effort, but at the same time, once you have done it, the experience can be very rewarding.

Coming from a small country, it is very helpful when your former students are in stakeholder positions; such as, when your former student is a civil servant in a public office or an editor in a media outlet. And then the question is whether we as academics told our students often enough that they can come back and rely on academic knowledge as a valuable input in a situation where they work as stakeholders and how they can benefit as collaborators. And sometimes we have, and sometimes we have not. This is something that we can reflect on. How do we build the understanding of stakeholder collaboration in our education? Is that something that our students see as a valuable contribution? Can they, for example, say: "Okay, but I did this as a student project! I know now, as a civil servant or as part of that editorial team that I can go back to "the academics" and bring them in and ask for advice"? That is something to be considered.

\section{And then the question is whether we as academics told our stu- dents often enough that they can come back and rely on academic knowledge as a valuable input in a situation where they work as stakeholders and how they can benefit as collaborators. - Pille Pruulmann-Vengerfeldt}

As a final point, also as something that other people have already reflected on whose questions are we studying? Are we studying our questions or are we studying our stakeholders' questions? And how do we make them meet? I had an interesting collaboration with an IT company that is developing a complicated privacy-preserving technology (Kanger, PruulmannVengerfeldt 2015). And they proposed that "we have this cool technology, but we do not really know what to use it for. Let us bring in some researchers who can help us to figure out how people are thinking about technology and privacy and using these kinds of privacy-preserving technologies". And they were very happy with the collaboration. They concluded: "This was so good. This gave us so much. It was so interesting."

Academically speaking, the level of knowledge we produced in that collaboration was not really that exciting. We could have probably done a lot of it just by doing a bit of literature review. We did 25 expert 
interviews across several countries in Europe, so we had a decent data collection. But I felt at the same time that, academically, the questions I was asking were not the deepest. It was not theory-inspired, and the findings could not really be used as new knowledge production for the field of audience studies. But for the field of IT, it was a massively-revolutionary new knowledge production - at least for that particular set of people. So, despite less than exciting academic results, the cross-disciplinary industry collaboration can be seen as having really positive potential.

We just have to find the right way to translate the knowledge that we produce into the stakeholder language - Pille PruulmannVengerfeldt

Sometimes I feel that, my contribution as audience researcher is enough when I go there and say "you know, what you say is not necessarily what audiences hear". And that in itself is already revolutionary new knowledge to lots of people. It may be 101 in media scholarship, but at the same time, when you have these people who say: "hmm, indeed, maybe they do have a different perspective in interpreting what I say," then you feel like "this is what I want to do!" I just want to go to people and say this one thing over and over again; that what you say is not necessarily what people hear. And I see that as a valid knowledge contribution to museum communication. What you put out there as an exhibition is not necessarily what people read of that exhibition. I see it still as a valid contribution to medical communication, where I have had to work with doctors, and a valid contribution in a host of different situations.

I want to end with perhaps the most interesting stakeholder collaboration that I have had. It was a project that was not actually intended to be a stakeholder collaboration at all. It was an autoethnography that I did on the Facebook use of disabled children (Pruulmann-Vengerfeldt 2018). But then, I have been invited now twice to speak to stakeholders; both parents and school staff, doctors and other medical personnel. And that experience itself has been so very rewarding as I have been able to share research insights from marginalised audiences who are at the receiving end of many of the services. And in this case, the stakeholders have been interested in this work mostly from the perspective of the academic contribution, but the added layer of a personal story has just helped. So, sometimes, we just have to find the right way to translate the knowledge that we produce into the stakeholder language, or into the collaborator's situation.

\section{ACKNOWLEDGEMENTS}

This manuscript presents the edited proceedings of a stakeholder collaboration panel that was organised during a joint NordMedia-ECREA event in Malmö, Sweden on August $21^{\text {st }}$ 2019. The joint event involved the audience research sections of both Nordmedia and ECREA (European Communication Research \& Education Association) and our gratitude goes to the organisers of this event. The manuscript is authored by the panellists (Kim Schrøder, Göran Bolin, Pille Runnell and Pille Pruulmann-Vengerfeldt) and the organiser/ moderator (David Mathieu) who took part in the event. The transcription of the panel was further edited by the management team of the Audience and Reception Studies section of ECREA - David Mathieu, Alessandro Nani and Vivi Theodoropoulou. Additionally, we wish to thank Tallinn University's Centre of Excellence in Media Innovation and Digital Culture, or MEDIT, for their support in providing resources for the transcription of the panel. 


\section{REFERENCES}

Bolin, Göran 1993. Videovåld i Sverige. En kommenterad filmografi. Stockholm: JMK.

Bolin, Göran 2000. 'Media Use, Taste and Aesthetic Production in Everyday Life. The Art of Film Swapping and Fanzine Writing. - Jostein Gripsrud (ed.), Sociology and Aesthetics, Kristiansand: Høgskoleforlaget, 41-54. Bolin, Göran; Bjur Jakob. 2014. 'Overcoming the barriers of access, newsworthiness and organisational forms of academy and stakeholders: Report from the stakeholder-academy deliberations on 19 September 2013. - Patriarche Geoffroy, Bilandzic Helena, Carpentier, Nico, Ponte Cristina, Schrøder Kim Christian, Zeller Frauke (eds.) Building bridges. Pathways to a greater societal significance for audience research. COST Action IS0906. Brussels.

Bourdieu, Pierre. 1993. The Field of Cultural Production. Essays on Art and Literature, Cambridge: Polity. Das, Ranjana, Ytre-Arne, Brita. 2018. The Future of Audiences: a Foresight Analysis of Interfaces and Engagement. Palgrave Macmillan.

Das, Ranjana, Ytre-Arne, Brita; Mathieu, David; Stehling, Miriam. 2018. 'Designing a Foresight Analysis Exercise on Audiences and Emerging Technologies: CEDAR's Analytical-Intuitive Balance'. - Ranjana Das, Brita Ytre-Arne (eds.), The Future of Audiences: a Foresight Analysis of Interfaces and Engagement. Palgrave Macmillan, 25-39.

Eriksson, Maria; Fleischer, Rasmus; Johansson, Anna; Snickars, Pelle; Vonderau, Patrick. 2019. Spotify teardown: Inside the black box of streaming music. MIT Press.

Habermas, Jürgen. 1968/1972. Knowledge and Human Interests. London: Heinemann Educational Books. Kanger, Laur; Pruulmann-Vengerfeldt, Pille. 2015. 'Social Need for Secure Multiparty Computation'. Laud, Peeter; Kamm, Liina (eds). Applications of Secure Multiparty Computation pp. 43-57. IOS Press.10.3233/978-1-61499-532-6-43.

Lazarsfeld, Paul Felix. 1941. 'Remarks on administrative and critical communications research'. Studies in Philosophy and Social Science, 91, 2-16.

Livingstone, Sonia. 2010. 'Giving People a Voice: On the Critical Role of the Interview in the History of Audience Research: - Communication, Culture \& Critique, 3(4), 566-571.

Lynd, Robert Staughton. 1939/1970. Knowledge for What? The Place of Social Science in American Culture. Princeton: Princeton University Press.

Mathieu, David; Stelhing, Miriam. 2017. 'Stakeholder consultation: approach'. - Ranjana Das, Brita YtreArne (eds.), Audiences, towards 2030: Priorities for audience analysis,37-39. CEDAR. http://epubs.surrey. ac.uk/842403/7/For\%20web\%20CEDAR-report.pdf (13 September 2020).
Möller, Gerda; Runnel, Pille; Põldaas, Mai. 2018.

'Muuseumide ja raamatukogude külastajate ja mittekülastajate uuring'. [Museum and library visitors and non-visitors survey] Eesti Kultuuriministeerium: Eesti Vabariigi Kultuuriministeerium. http://kul.ee/ sites/kulminn/files/muuseumide_ja_raamatukogude_ kulastajate_ja_mittekulastajate_uuringu_lopparuanne_0.pdf (12 September 2020).

Paßmann, Johannes; Boersma, Asher. 2017. ‘Unknowing Algorithms On Transparency of Unopenable Black Boxes'. - Mirko Tobias Schäfer, Karin van Es (eds.),

The Datafied Society, 139-146. Amsterdam University Press.

Patriarche, Geoffroy; Bilandzic, Helena; Carpentier, Nico; Ponte Cristina; Schrøder, Kim Christian; Zeller, Frauke. 2014 Building bridges. Pathways to a greater societal significance for audience research. COST Action IS0906. Brussels.

SOU 1993:39: En gräns för censuren. Delbetänkande från Våldsskildringsrådet, Stockholm: Allmänna förlaget.

Pruulmann-Vengerfeldt, Pille. 2018. 'CHARGE on: Digital Parenting of a Child with Rare Genetic Syndrome with the Help of Facebook Group. Macheroni Giovanna, Jorge Ana, Ponte Christina.

Digital Parenting: The challenges for Families in the Digital Age. Göteborg: Nordicom, 189-198.

Pruulmann-Vengerfeldt, Pille; Tatsi, Taavi; Runnel, Pillle; Aljas, Agnes. 2014. 'Researching Audience Participation in Museums: A Multi-Method and MultiSite Interventionist Approach'. - Geoffroy Patriarche, Helena Bilandzic, Jakob Linaa Jensen, Jelena Jurišić (eds). Audience Research Methodologies Between Innovation and Consolidation, 87-106. Routledge. Runnel, Pille; Pruulmann-Vengerfeldt, Pille. 2014. Democratising the Museum: Reflections on Participatory Technologies. Peter Lang Verlag. Schrøder, Kim. Christian; Hansen, Søren Esben. 2005. 'Beyond duality: Danes' views on Denmark and the European Union 2001'. - Richard Robyn (ed.), The changing face of European identity (37-63). London and New York: Routledge

Schrøder, Kim Christian; Larsen, Bent Steeg. 2010.

'The shifting cross-media news landscape: Challenges for news producers'. - Journalism Studies 11 (4), 524-534.

Ytre-Arne, Brita; Das, Ranjana. 2019. 'An Agenda in the Interest of Audiences: Facing the Challenges of Intrusive Media Technologies'. - Television \& New Media, 20(2), 184-198. 